\title{
Development, Validation and Application of a Method for Monitoring of Essential and Semi-Essential Free Amino Acids in Infant Formulae and Follow-up Milks Using HPLC/Diode Array Detection
}

\author{
Eulália Mendes, Isabel M. P. L. V. O. Ferreira, A. M. Gomes and Margarida A. Ferreira \\ CEQUP/Laboratório de Bromatologia, Faculdade de Farmácia, Universidade do Porto, \\ R. Aníbal Cunha 164, Porto, Portugal
}

Keywords Free amino acid, infant formula, follow-up milk, high performance liquid chromatography-diode array

The infant formulae used in baby nutrition are based upon cow's milk proteins, casein or whey protein hydrolyzates or soy protein preparations. Follow-up milks are given to infants after $4-6$ months of age to make the transition from human or infant formulae to cow's milk. In order to improve the nutritional value of these artificial formulae and make them comparable to the human milk standard, supplementation with essential and semi-essential amino acids is recommended.

The first aim of this research was to develop an adequate, sensitive, reproducible, accurate and specific analytical procedure for the quantification of the 8 essential amino acids (threonine, phenylalanine, valine, lysine, isoleucine, methionine, leucine, tryptophan) and 6 amino acids considered semi-essential for infants (cysteine, cystine, taurine, tyrosine, histidine and arginine) in complex matrices such as infant formulae and follow-up milks.

For the analysis of amino acids, the methods which have gained increasing importance involve precolumn derivatization with a mixture of $o$-phthalaldehyde (OPA) and 2-mercaptoethanol and separation by reversed-phase high performance liquid chromatography (RP-HPLC) with different eluents ${ }^{2-7}$ because of the shorter analysis time and increased sensitivity compared with the classical amino acid analyzers. The analytical procedure optimized in our work was based on this method, owing to the requirement for accurate quality control of the infant formulae and follow-up milks, and hence a rapid and easy-to-handle method for specific identification of amino acid supplementation. With respect to the detection method, although fluorometric detection with a high sensitivity may be recommended, it requires extreme care to ensure optimum results. For this reason, UV detection using the Diode array detector was chosen. Rapidity, accuracy, peak purity analysis and a lower chance of detection error are advantages of this method.

The second aim of this research was the monitoring of essential and semi-essential free amino acids in infant formulae and follow-up milks available on the local market.

\section{Experimental}

\section{Apparatus and operating conditions}

The chromatographic analyses were carried out in a JASCO high performance liquid chromatograph equipped with two type PU-980 pumps and a type AS950 auto-sampler. A C18 (S10ODS2) chromatographic column; a JASCO multiwavelength diode array detector MD-910 and a Borwin PDA Controller Software were also used. The eluent used was a gradient of 0.05 $\mathrm{M}$ phosphate buffer pH 5.3 (A)/methanol (B). Elution was performed at a solvent flow rate of $0.8 \mathrm{ml} / \mathrm{min}$ with a linear gradient from $60 \%$ of B to $40 \%$ of B within 20 min, keeping these conditions during $8 \mathrm{~min}$ and returning to the initial conditions within $2 \mathrm{~min}$. Detection was accomplished with the diode-array at $350 \mathrm{~nm}$.

\section{Reagents and solutions}

All reagents used were (p.a.) from Merck. L-Amino acids kit and $o$-phthalaldehyde were from Sigma Chemicals Co.

\section{Sample preparation and derivatization procedure}

Sample preparation and derivatization of amino acids were performed as described by Ferreira et $a l^{7}$

\section{Sampling}

Twenty-five samples were assayed, including 14 infant formulae based on cow's milk proteins, 6 followup milks, 4 infant formulae based on casein or whey protein hydrolyzates and 1 infant formula based on soy protein.

\section{Statistical analysis}

Data are represented as the mean \pm standard deviation. Analysis of variance was used to determine the effects 
of type of brand, on the one hand, and type of formulation on the other, on the free amino acids contents. Fisher's protected least significant difference $t$-test (PLSD) at the 5\% significance level was applied to all experimental results to assess intrapair significant differences. All statistical analyses were done with the Statview ${ }^{\mathrm{TM}} 4.0$ statistical package (Abacus Concepts, Berkeley CA 94 704-1038, USA).

\section{Results and Discussion}

Under the assay conditions described, a linear relationship between the concentration of amino acids and the UV absorbance at $350 \mathrm{~nm}$ was obtained. This linearity was maintained over the concentration range $0.25-100 \mathrm{mg} / \mathrm{l}$ for threonine, taurine, tyrosine, phenylalanina, isoleucine, leucine; $0.5-100 \mathrm{mg} / \mathrm{l}$ for histidine, arginine, methionine and valine; $1.0-100 \mathrm{mg} / \mathrm{l}$ for tryptophan and cystine and $2.0-100 \mathrm{mg} / \mathrm{l}$ for lysine. The correlation coefficient for each standard curve invariably exceeded 0.999 .

The detection limits (calculated as the concentration corresponding to three times the background noise, obtained with 10 determinations) were $0.15 \mathrm{mg} / \mathrm{l}$ for threonine, taurine, tyrosine, phenylalanine, isoleucine and leucine; $0.25 \mathrm{mg} / \mathrm{l}$ for histidine, arginine, methionine and valine. For tryptophan and cystine the detection limit was $0.5 \mathrm{mg} / \mathrm{l}$ and for lysine it was $1.0 \mathrm{mg} / \mathrm{l}$. The detection limits found were comparable to the values referred in literature for diode array detection. ${ }^{2}$

\section{Validity of the method}

No interference of other amino acids (L-alanine, Lproline, glycine, L-serine, L-asparagine, L-aspartic acid, L-glutamic acid) was observed.

The precision of the analytical method was evaluated by measuring 10 times the peak height of one sample. The relative standard deviation (RSD) was $1.4 \%$ (the only amino acid detected in this infant formula was taurine, concentration of $42.6 \mathrm{mg} / 100 \mathrm{~g}$ ).

Recovery studies were performed to verify the effectiveness of the extraction step and the accuracy of the proposed method. Over $95 \%$ recoveries of amino acids added to a randomly chosen infant formula were observed for all amino acids, which confirm no interference effects due to matrix composition.

This method featured a rapid and convenient separation together with a high degree of precision and accuracy, and seemed to be suitable for routine analyses. The short analysis time of 20 min was a good advantage.

\section{Application of the method to infant formulae and follow-up milks}

The developed method was applied to the monitorization of essential and semi-essential free amino acids in infant formulae and follow-up milks commercially available on the local market. The results obtained are shown in Tables 1, 2 and 3.

As apparent from Tables 1 and 2, milk infant formulae and follow-up milks provided similar qualitative profiles of free amino acids, but quantitatively significant differences were sometimes observed. The prevailing amino acids in both formulae were threonine and taurine but their concentrations were affected differently by the type of formulation. Analysis of variance showed that this variable was not significant for threonine $(p=0.478)$, in contrast to the taurine content which was significant affected $(p=0.0012)$; follow-up milks presented lower concentrations of taurine (Tables 1 and 2).

With respect to the influence of the type of brand, data pertaining to the amino acids threonine and taurine

Table 1 Results obtained in the monitorization of free essential and semi-essential amino acids in milk infant formulae

\begin{tabular}{ccccccc}
\hline Sample & Threonine & Arginine & Taurine & Valine & Isoleucine & Leucine \\
\hline 1 & $21.6 \pm 2.2^{\mathrm{c}}$ & $5.24 \pm 0.59$ & $37.9 \pm 1.2^{\mathrm{c}, \mathrm{f}}$ & n.d. & n.d. & n.d. \\
2 & $14.5 \pm 0.1^{\mathrm{d}}$ & n.d. & $30.8 \pm 0.2^{\mathrm{d}, \mathrm{h}}$ & n.d. & n.d. & n.d. \\
3 & $33.4 \pm 3.5^{\mathrm{e}}$ & n.d. & $38.0 \pm 2.5^{\mathrm{c}, \mathrm{f}}$ & n.d. & n.d. & n.d. \\
4 & $3.88 \pm 0.00^{\mathrm{f}}$ & n.d. & $38.0 \pm 2.3^{\mathrm{f}}$ & n.d. & n.d. & n.d. \\
5 & $29.7 \pm 1.3^{\mathrm{b}, \mathrm{g}}$ & traces & $44.7 \pm 0.7^{\mathrm{g}}$ & $1.69 \pm 0.33$ & $1.60 \pm 0.09$ & $1.86 \pm 0.07$ \\
6 & $31.5 \pm 1.0^{\mathrm{e}, \mathrm{g}}$ & n.d. & $33.2 \pm 2.1^{\mathrm{d}}$ & n.d. & n.d. & n.d. \\
7 & n.d. $^{\mathrm{a}}$ & n.d. & $28.2 \pm 2.6^{\mathrm{a}, \mathrm{h}}$ & n.d. & n.d. & n.d. \\
8 & n.d. $^{\mathrm{a}}$ & n.d. & $17.8 \pm 1.1^{\mathrm{i}}$ & n.d. & n.d. & n.d. \\
9 & n.d. $^{\mathrm{a}}$ & n.d. & $32.6 \pm 1.3^{\mathrm{d}}$ & n.d. & n.d. & n.d. \\
10 & $1.41 \pm 0.01^{\mathrm{a}, \mathrm{f}}$ & n.d. & $5.63 \pm 0.4^{\mathrm{e}}$ & n.d. & n.d. & n.d. \\
11 & traces $^{\mathrm{a}}$ & n.d. & $24.5 \pm 0.4^{\mathrm{a}}$ & n.d. & n.d. & n.d. \\
12 & $1.60 \pm 0.01^{\mathrm{a}, \mathrm{f}}$ & n.d. & $10.4 \pm 0.01^{\mathrm{b}}$ & n.d. & n.d. & n.d. \\
13 & $26.6 \pm 2.6^{\mathrm{b}}$ & n.d. & $34.5 \pm 2.4^{\mathrm{c}, \mathrm{d}}$ & n.d. & n.d. & n.d. \\
14 & $14.3 \pm 0.8^{\mathrm{d}}$ & $10.9 \pm 0.9$ & $55.6 \pm 0.6^{\mathrm{j}}$ & n.d. & n.d. & n.d. \\
\hline
\end{tabular}

Values are expressed as mean \pm standard deviation of two determinations ( $\mathrm{mg}$ of amino acid/100 $\mathrm{g}$ of product). The amino acids that are not tabulated were undetectable in the assayed infant formulae. a, b, c, d, e, f, g, h, i, j- means in columns without common superscripts are significantly different $(p<0.05) ; n=2$. 
Table 2 Results obtained in the monitorization of free essential and semi-essential amino acids in follow-up milks

\begin{tabular}{ccccc}
\hline Sample & Threonine & Arginine & Taurine & Tyrosine \\
\hline 15 & $11.2 \pm 1.4^{\mathrm{a}}$ & n.d. & $39.83 \pm 0.02^{\mathrm{a}}$ & n.d. \\
16 & $21.5 \pm 0.76^{\mathrm{b}}$ & n.d. & $4.47 \pm 0.31^{\mathrm{b}}$ & n.d. \\
17 & $21.6 \pm 2.0^{\mathrm{b}}$ & n.d. & $2.12 \pm 0.06^{\mathrm{c}}$ & n.d. \\
18 & $2.88 \pm 0.37^{\mathrm{c}}$ & $3.88 \pm 0.4$ & traces $^{\mathrm{d}}$ & $53.4 \pm 0.84$ \\
19 & $17.1 \pm 2.15^{\mathrm{d}}$ & n.d. & $34.53 \pm 0.33^{\mathrm{e}}$ & n.d. \\
20 & $19.57 \pm 0.53^{\mathrm{b}, \mathrm{d}}$ & n.d. & $1.01 \pm 0.08^{\mathrm{f}}$ & n.d. \\
\hline
\end{tabular}

Values are expressed as mean \pm standard deviation of two determinations ( $\mathrm{mg}$ of amino acid/100 $\mathrm{g}$ of product). The amino acids that are not tabulated were undetectable in the assayed infant formulae.

$\mathrm{a}, \mathrm{b}, \mathrm{c}, \mathrm{d}, \mathrm{e}, \mathrm{f}$, means in columns without common superscripts are significantly different $(p<0.05) ; n=2$

indicate significant differences $(p<0.001)$, among the commercial brands of infant formulae which are confirmed by their high $F$-values ( $F=121.49$ and $F=95.20$, respectively). Among the assayed samples, 50\% showed low or not detected amounts of threonine (brands 4, 7 -12). The remaining samples presented higher concentrations of threonine, varying between $14.3 \pm 0.1-33.4 \pm 3.5 \mathrm{mg} / 100 \mathrm{~g}$ of product, probably due to different levels of supplementation (low levels, samples 2 and 14; medium levels, samples 1, 5 and 13; high levels, samples 3 and 6).

A large variability among commercial brands was also noticed for taurine (as apparent from the high $F$ values) but, in contrast with threonine, all the assayed infant formulae were supplemented with taurine at different concentrations varying between $5.63 \pm 0.24$ $\mathrm{mg} / 100 \mathrm{~g}$ of product and ten times more 55.6 \pm 0.6 $\mathrm{mg} / 100 \mathrm{~g}$ product (Table 1 ).

With respect to the effect of brand of follow-up milks on the content of threonine the dispersion among samples was lower $(F=41.3)$ (but the sampling is also inferior); most of the samples contained levels of threonine around $20 \mathrm{mg} / 100 \mathrm{~g}$ product (samples $16,17,19,20$ ) as shown in Table 2. Sample 18 was the only follow-up milk with a concentration which seriously deviated from the mean value. In contrast, a large variability among commercial brands for taurine $(F=7142.9)$ was reported for the follow-up milks assayed. Concentrations varied between trace amounts and $39.83 \pm 0.02 \mathrm{mg} / 100 \mathrm{~g}$. No significant statistical similarities were found between any of these samples $(p=0.0001)$ as indicated in Table 2.

It is important to point out, that the major occurring free amino acid in infant formulae, taurine, takes part in biochemical reactions of major importance. Neonates and infants have a very limited ability to synthesize taurine; they are specially prone to develop taurine deficiency and depend on an external supply. ${ }^{8}$ These facts justify the taurine occurrence, specially in infant formulae.

With respect to other free amino acids monitored, arginine was detected, although at very different levels $(p<0.05)$, in a few samples within the infant formulae and in one sample of follow-up milks. The essential free amino acids, namely valine, leucine and isoleucine, were all found in one single infant formula (Table 1) and the semi-essential tyrosine was only detected in one follow-up milk (Table 2).

The infant formula sample based on soya proteins was supplemented with taurine and methionine, which is in agreement with U. E. Legislation. ${ }^{1}$

Products based on casein or whey protein hydrolyzates showed, in general, high concentrations of essential and semi-essential amino acids compared to the other infant formulae analyzed (Table 3). However, the levels at which the amino acids were found varied

Table 3 Results obtained in the monitorization of free essential and semi-essential amino acids in infant formulae based on milk protein hydrolyzates ${ }^{\mathrm{a}, \mathrm{b}}$ and infant formula based on soya protein ${ }^{\mathrm{a}, \mathrm{c}}$

\begin{tabular}{|c|c|c|c|c|c|c|c|}
\hline Sample & Histidine & Threonine & Taurine & Arginines & Tyrosine & Tryptophan & Cystine \\
\hline $21^{\mathrm{b}}$ & vest. & $2.85 \pm 0.00$ & $34.5 \pm 1.9$ & $11.0 \pm 1.2$ & $22.1 \pm 1.1$ & $18.0 \pm 1.1$ & $143 \pm 4.1$ \\
\hline $22^{\mathrm{b}}$ & $6.26 \pm 0.10$ & $1.32 \pm 0.10$ & $36.0 \pm 2.1$ & $19.2 \pm 2.5$ & $27.9 \pm 1.7$ & $18.2 \pm 1.0$ & $66.4 \pm 2.8$ \\
\hline $23^{\mathrm{b}}$ & $53.0 \pm 2.2$ & $2.45 \pm 0.11$ & $28.1 \pm 1.0$ & $29.0 \pm 1.1$ & $55.1 \pm 2.6$ & $16.2 \pm 1.1$ & $88.7 \pm 3.0$ \\
\hline $24^{\mathrm{b}}$ & $7.80 \pm 0.11$ & $8.00 \pm 0.05$ & $48.5 \pm 2.1$ & $19.8 \pm 1.1$ & $70.6 \pm 2.1$ & $5.58 \pm 0.4$ & $80.4 \pm 2.1$ \\
\hline $25^{\mathrm{c}}$ & n.d. & n.d. & $32.7 \pm 0.4$ & n.d. & n.d. & n.d. & n.d. \\
\hline Sample & Methionine & Valine & \multicolumn{2}{|c|}{ Phenylalanine } & & Isoleucine & Leucine \\
\hline $21^{\mathrm{b}}$ & $8.07 \pm 0.70$ & $10.1 \pm 0.8$ & \multicolumn{2}{|c|}{$27.7 \pm 2.0$} & 0.03 & $12.0 \pm 1.2$ & $40.5 \pm 2.0$ \\
\hline $22^{\mathrm{b}}$ & $12.2 \pm 2.0$ & $12.1 \pm 0.9$ & \multicolumn{2}{|c|}{$31.0 \pm 1.5$} & 0.08 & $18.6 \pm 0.1$ & $55.5 \pm 2.6$ \\
\hline $23^{\mathrm{b}}$ & $21.5 \pm 1.9$ & $21.8 \pm 2.2$ & \multicolumn{2}{|c|}{$24.0 \pm 2.1$} & 1.01 & $20.2 \pm 2.3$ & $77.1 \pm 3.6$ \\
\hline $24^{\mathrm{b}}$ & $20.5 \pm 1.5$ & $25.9 \pm 2.6$ & \multicolumn{2}{|c|}{ n.d. } & 2.03 & $12.0 \pm 1.1$ & $56.7 \pm 2.1$ \\
\hline $25^{\mathrm{c}}$ & $99.5 \pm 2.5$ & n.d. & \multicolumn{2}{|c|}{ n.d. } & & n.d. & n.d. \\
\hline
\end{tabular}

a. Values are expressed as mean \pm standard deviation of two determinations ( $\mathrm{mg}$ of amino acid/100 $\mathrm{g}$ of product). The amino acids that are not tabulate were undetectable in the assayed infant formulae. b. Infant formulae based on milk protein hydrolyzate. c. infant formulae based on soya protein. 
significantly between these product types, an observation which may reflect the different degrees of hydrolysis of the respective hydrolyzates employed.

Financial support is provided by JNCT (Projecto PBIC/ C/TPR/2564/95).

\section{References}

1. 91/3211 EC Directive, J. O. E. C., L-175/35, 4. 7. 91.

2. R. Schuster, J. Chromtogr., 431, 271 (1988).

3. B. N. Jones, P. Paabo and S. Stein, J. Liq. Chromatogr., 4,
565 (1981).

4. C. R. Krishnamurti, A. M. Heindze and G. Galzy, J. Chromatogr., 315, 321 (1984).

5. K. Mopper and D. Delmas, Anal. Chem., 56, 2557 (1984).

6. L. E. Weissberger and M. K. Armstrong, J. Chromatogr. Sci., 22, 438 (1984).

7. I. M. P. L. V. O. Ferreira, M. V. Nunes, E. Mendes, F. Remião and M. A. Ferreira, J. Liq. Chromatogr., 20, 1269 (1997).

8. G. E. Gaull, Pediatrics, 83, 433 (1989).

(Received December 16, 1997) (Accepted March 27, 1998) 